\title{
Retraction: Engineering of extracellular vesicles as drug delivery vehicles
}

\author{
Sung-Man Kim', Han-Soo Kim ${ }^{2}$ \\ ${ }^{1}$ Medical Management Department, ${ }^{2}$ Department of Biomedical Sciences, College of Medical Convergence, Catholic Kwandong University, \\ Gangneung-si, Gangwon-do, Republic of Korea \\ Correspondence to: Han-Soo Kim. Department of Biomedical Sciences, College of Medical Convergence, Catholic Kwandong University, 24, Beomil- \\ ro 579 beon-gil, Gangneung-si, Gangwon-do, 25601, Republic of Korea. Email: hankim63@gmail.com.
}

doi: $10.21037 /$ sci.2018.05.02

View this article at: http://dx.doi.org/10.21037/sci.2018.05.02

Retraction to: Stem Cell Investig 2017;4:74

The article "Engineering of extracellular vesicles as drug delivery vehicles" (doi: 10.21037/sci.2017.08.07) published in Stem Cell Investigation in September 2017 needs to be retracted as part of Figure 1 was adapted from some other publication and the authors did not obtain the copyright permission. I sincerely apologize for the oversight.

All authors agree to the retraction of the paper.

doi: $10.21037 /$ sci.2018.05.02

Cite this article as: Kim SM, Kim HS. Retraction:

Engineering of extracellular vesicles as drug delivery vehicles.

Stem Cell Investig 2018;5:15. 